02

\title{
Влияние пространственной ориентации наностержней ZnO на спектр люминесценции
}

\author{
(C) С.С. Курбанов, Ш.З. Уролов, З.Ш. Шаймарданов \\ Институт ионно-плазменных и лазерных технологий АН Республики Узбекистан, \\ 100125 Ташкент, Узбекистан \\ e-mail: saidislam_kurbanov@yahoo.com
}

Поступила в редакцию 07.09.2017 г.

С использованием гидротермального метода на стеклянных подложках, покрытых проводящей оксидной пленкой, синтезированы наностержни оксида цинка $(\mathrm{ZnO})$. Длина наностержней 2-2.5 $\mu \mathrm{m}$, а диаметр $70-200 \mathrm{~nm}$. В них под воздействием УФ излучения возбуждается люминесценция с максимумом при $382 \mathrm{~nm}$. С изменением пространственной ориентации наностержней относительно системы регистрации люминесценции появляется фиолетовая полоса люминесценции в районе $400 \mathrm{~nm}$. Зависимость спектра люминесценции от пространственной ориентации наностержней, возможно, связана с расположением центров свечения фиолетовой полосы преимущественно в приповерхностной области наностержней.

DOI: $10.21883 /$ OS.2018.02.45524.198-17

\section{Введение}

Оксид цинка $(\mathrm{ZnO})$, широкозонный полупроводник (ширина запрещенной зоны $3.37 \mathrm{eV}$ при комнатной температуре) с большой энергией связи свободного экситона $(60 \mathrm{meV})$, состоящий из элементов II-VI групп важный функциональный материал, применяемый во многих областях техники [1]. Будучи оптически прозрачным в видимом и ближнем УФ диапазонах и благодаря хорошей проводимости $\mathrm{ZnO}$ используется для производства компонентов полупроводниковых приборов, датчиков, УФ фильтров, в дисплеях и солнечных элементах в качестве прозрачного проводящего электрода [2]. Кроме этого, $\mathrm{ZnO}$ является высокоэффективным источником излучения УФ диапазона, его одномерные структуры (наностержни и нанопроволоки) позволяют получить лазерную генерацию [3], тонкие пленки считаются перспективным материалом для создания фотодиодов [1].

Одномерные структуры оксида цинка являются удобными объектами в исследовании физических явлений, связанных с размерностью структуры, особенностями геометрии и пространственным расположением центров излучения в этих структурах [4]. Спектр фотолюминесценции оксида цинка при комнатной температуре наряду с краевой (экситонной) люминесценцией при $380 \mathrm{~nm}$ содержит широкую полосу свечения в районе $500-650 \mathrm{~nm}$, обусловленную собственными дефектами. Эта полоса обычно рассматривается состоящей из фиолетово-синей $(390-460 \mathrm{~nm})$, зеленой $(500-520 \mathrm{~nm})$, желто-оранжевой $(560-600 \mathrm{~nm})$ и красной $(650 \mathrm{~nm})$ полос. Проявление и доминирование той или иной полосы люминесценции зависят от метода и температуры синтеза, температуры, продолжительности и атмосферы постсинтезной обработки и т.д.

Существуют разные мнения по поводу источников возникновения этих полос излучения. В частности, фиолетовая полоса люминесценции (ПЛ) в районе $400 \mathrm{~nm}$ приписывается вакансиям цинка [5-8], голубая ПЛ в районе 420-460 nm - межузельному цинку [9], зеленая ПЛ - кислородной вакансии $[10,11]$ и вакансии цинка [12], а желто-оранжевая ПЛ - межузельному кислороду $\left(\mathrm{O}_{i}\right)[13-15]$.

В настоящей работе представлены результаты исследований зависимости спектра фотолюминесценции наностержней $\mathrm{ZnO}$ от их пространственной ориентации. В наностержнях $\mathrm{ZnO}$, синтезированных гидротермальным методом, под воздействием УФ излучения возбуждается люминесценция при $382 \mathrm{~nm}$. Обнаружено, что при изменении ориентации наностержней относительно оси регистрации люминесценции появляется вторая ПЛ в районе $400 \mathrm{~nm}$. Установлено, что с изменением угла между осью регистрации люминесценции и направлением роста наностержней происходит увеличение интенсивности фиолетовой полосы люминесценции, в то время как интенсивность краевой (экситонной) люминесценции уменьшается. Полоса люминесценции в районе $400 \mathrm{~nm}$ приписывается вакансиям цинка, локализованным преимущественно в приповерхностной области наностержня.

\section{Экспериментальная часть}

Наностержни ZnO были выращены с использованием низкотемпературного гидротермального метода. Водные растворы нитрата цинка гексогидрата $\left(\mathrm{Zn}\left(\mathrm{NO}_{3}\right)_{2} \cdot 6 \mathrm{H}_{2} \mathrm{O}\right)$ и гексаметилтетрамина $\left(\mathrm{C}_{6} \mathrm{H}_{12} \mathrm{~N}_{4}\right)$ приготавливались отдельно и затем смешивались. Концентрация обоих растворов бралась равной $0.1 \mathrm{M}$. Смесь перемешивалась с помощью магнитной мешалки в течение $30 \mathrm{~min}$, пока не образовался прозрачный и однородный раствор. Затем раствор был перемещен в стальной автоклав с внутренним тефлоновым покрытием, куда предварительно были помещены активной поверхностью 


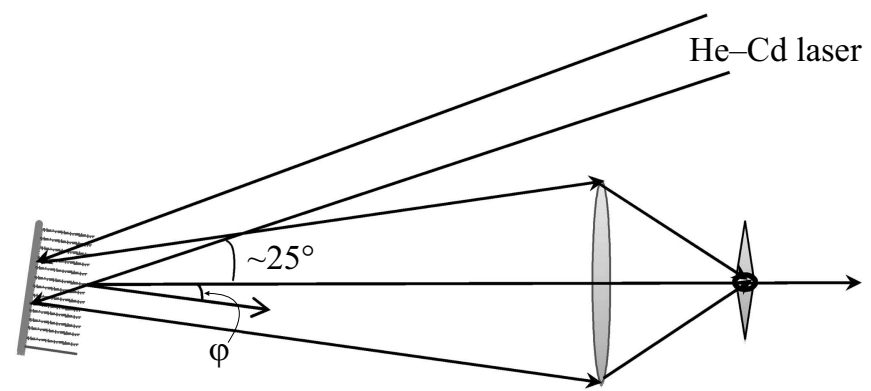

Рис. 1. Схема регистрации люминесценции наностержней $\mathrm{ZnO}, \varphi-$ угол между нормалью к поверхности подложки с наностержнями и осью регистрации люминесценции.

вниз заранее подготовленные стеклянные пластинки с зародышами $\mathrm{ZnO}$. В заключение автоклав плотно закрывался и помещался в термостабилизированную ванну с водой. Гидротермальная реакция протекала при температуре $90^{\circ} \mathrm{C}$ в течение $5 \mathrm{~h}$.

После окончания реакции синтеза автоклав вынимался из ванны с водой и остывал до комнатной температуры при естественных условиях. После охлаждения образцы были извлечены из автоклава и несколько раз промывались в деионизированной воде и высушивались на воздухе.

Подготовка подложек с зародышами $\mathrm{ZnO}$ происходила следующим образом: стеклянные пластинки с проводящей ITO-пленкой очищались в ультразвуковой ванне в течение $15 \mathrm{~min}$ в ацетоне и этиловом спирте. Зародыши $\mathrm{ZnO}$ создавались с использованием раствора ацетата цинка дигидрата $\left(\mathrm{Zn}\left(\mathrm{CH}_{3} \mathrm{COO}\right)_{2} \cdot 2 \mathrm{H}_{2} \mathrm{O}\right)$ в этиловом спирте $(5 \mathrm{mM})$. Этот раствор наносился на подложки методом центрифугирования (spin coating) и высушивался на воздухе. Процесс повторялся несколько раз, что позволило увеличить плотность образующихся зародышей $\mathrm{ZnO}$. Полученные подложки отжигались на воздухе при температуре $250^{\circ} \mathrm{C}$ в течение $30 \mathrm{~min}$. Температура отжига немного выше температуры разложения ацетата цинка дигидрата и формирования нанокристаллов $\mathrm{ZnO}$.

Морфология образцов исследовалась с помощью сканирующего электронного микроскопа (СЭМ) (PHILIPS XL-30). Образцы были установлены на специальном поворотном столике, что давало возможность менять угол $\varphi$ между направлением роста наностержней и осью регистрации люминесценции (рис. 1). Спектры люминесценции возбуждались с помощью лазера $\mathrm{He}-\mathrm{Cd}$ $(325 \mathrm{~nm}, 50 \mathrm{~mW})$ и регистрировались посредством монохроматора SPEX, ФЭУ Hamamatsu R943-02 и синхронного детектора.

\section{Результаты и их обсуждение}

На рис. 2 представлены микрофотографии наностержней $\mathrm{ZnO}$, полученные СЭМ. Как видно, длина наностержней $\mathrm{ZnO} 2-2.5 \mu \mathrm{m}$, а диаметр 70-200 nm. Торцы наностержней $\mathrm{ZnO}$ имеют правильную гексогональную форму, и наностержни растут преимущественно перпендикулярно подложке.

Исследования показали, что под воздействием УФ излучения наностержни $\mathrm{ZnO}$ проявляют люминесценцию с максимумом при $382 \mathrm{~nm}$. На рис. 3 (кривая 1) представлен спектр люминесценции наностержней $\mathrm{ZnO}$, полученный при условии, что подложка перпендикулярна оси регистрации излучения. Спектр люминесценции содержит только один максимум. Согласно литературе наблюдаемая люминесценция относится к рекомбинации свободных экситонов $\mathrm{ZnO}$ [1].

Исследования показали, что спектр и интенсивность люминесценции наностержней зависят от угла регистрации. С изменением угла регистрации излучения при неизменном возбуждении в спектре начинает проявляться новая ПЛ в районе $400 \mathrm{~nm}$. На рис. 3 (кривые 2, 3 и 4) показаны спектры люминесценции, регистрированные при $\varphi=20,35$ и $50^{\circ}$. Как видно, с увеличением $\varphi$ происходит перераспределение интенсивности между ПЛ при

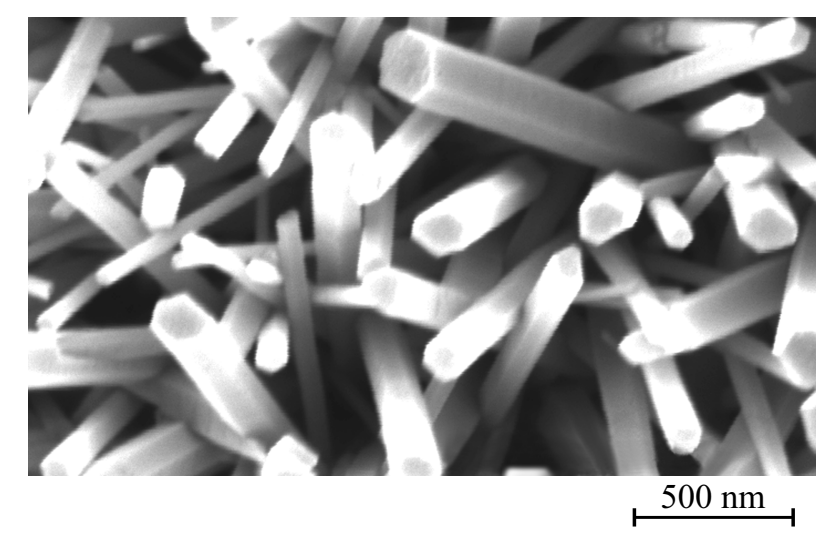

Рис. 2. Микрофотографии наностержней $\mathrm{ZnO}$, полученные СЭМ.

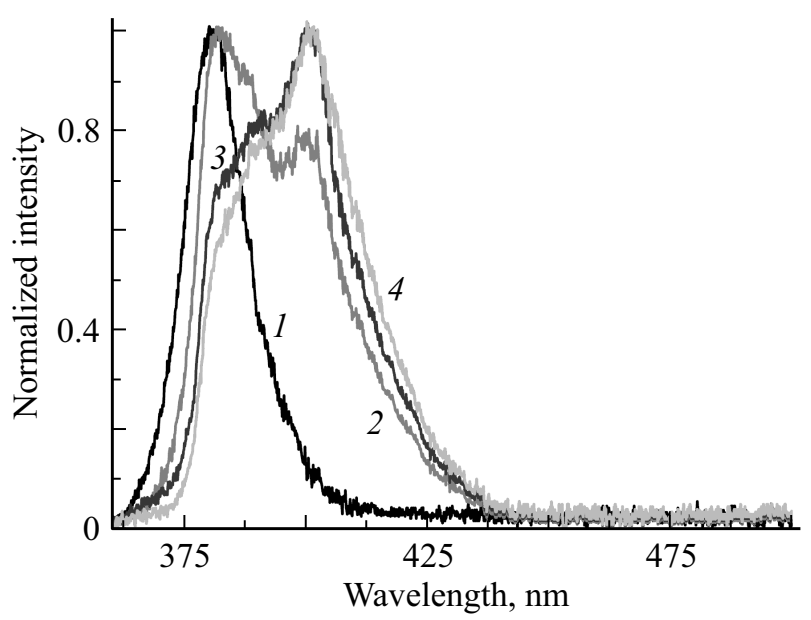

Рис. 3. Спектры люминесценции наностержней $\mathrm{ZnO}$, peгистрированные при различных углах $\varphi$ между нормалью к поверхности подложки с наностержнями и осью регистрации люминесценции: $1-0,2-20^{\circ}, 3-35^{\circ}, 4-50^{\circ}$. 


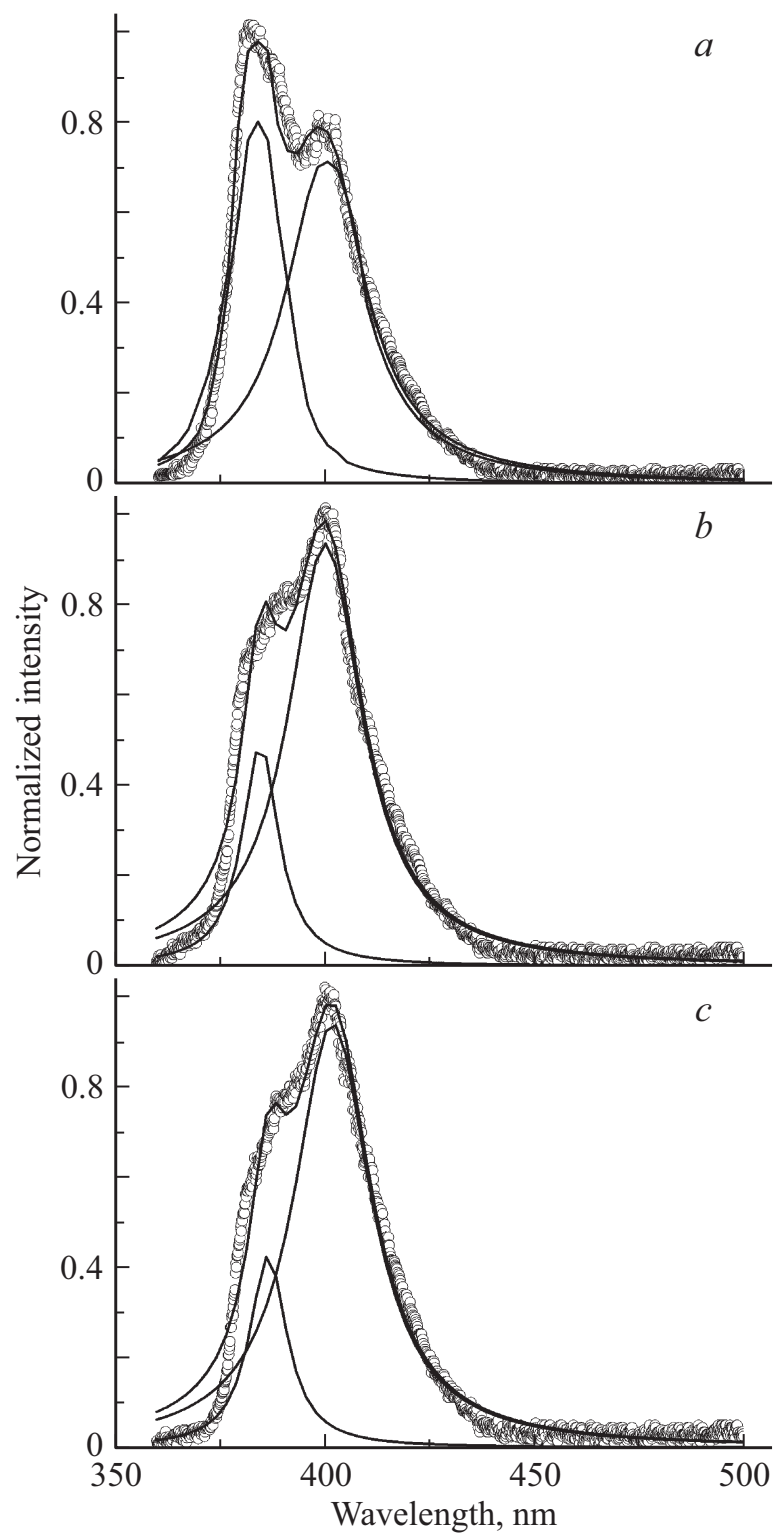

Рис. 4. Разложение на лоренцевы компоненты спектров люминесценции наностержней $\mathrm{ZnO}$, полученных при различных углах $\varphi$ между нормалью к поверхности подложки с наностержнями и осью регистрации люминесценции: $\varphi=20^{\circ}(a)$, $35^{\circ}(b), 50^{\circ}(c)$. Кружки - экспериментальные данные, сплошные кривые - лоренцевы компоненты.

$382 \mathrm{~nm}$ и новой ПЛ в районе $400 \mathrm{~nm}-$ интенсивность первой полосы уменьшается, а интенсивность второй растет. Необходимо заметить, что увеличение угла регистрации приводит к уменьшению общей интегральной интенсивности люминесценции. Полученные спектры люминесценции были разложены на составляющие при предположении, что полосы описываются функцией Лоренца. Кроме спектра люминесценции, полученного при $\varphi=0$, остальные спектры можно представить состоящими из двух лоренцевых компонент с максимумами при $\sim 383$ и $401 \mathrm{~nm}$ (рис. 4). Интегральные интенсивности этих компонент изменяются в противоположных направлениях с ростом $\varphi-$ интенсивность первой полосы уменьшается, а интенсивность второй растет.

Как было отмечено во введении, фиолетовая ПЛ в районе $400 \mathrm{~nm}$ приписывается вакансиям цинка [5-8] и наблюдается в структурах $\mathrm{ZnO}$, выращенных в условиях с избытком кислорода, независимо от способов синтеза. При гидротермальном методе синтеза реакция протекает в водной среде с избытком кислорода, что способствует образованию вакансий цинка. Теоретические исследования предсказывают, что в условиях синтеза $\mathrm{ZnO}$ с избытком кислорода энтальпия образования вакансий цинка меньше, чем у других дефектов $[16,17]$, и они могут выступать доминирующими дефектами. Учитывая эти данные и наши результаты, можно предположить, что фиолетовая ПЛ в районе $400 \mathrm{~nm}$ в наностержнях $\mathrm{ZnO}$ также обусловлена дефектами, связанными с вакансией цинка или их комплексами. Как было теоретически предсказано, для вакансии цинка переходной уровень $(0 /-1)$ лежит выше потолка валентной зоны на $\sim 0.45[16]$ или $\sim 0.3 \mathrm{eV}[17]$, а переходной уровень $(-1 /-2)-$ на $\sim 0.8[16]$ или $0.7 \mathrm{eV}$ [17]. Исходя из этого переходы электрона из зоны проводимости или мелкого донорного уровня на однозарядный акцепторный уровень вакансии цинка могут дать люминесценцию с длиной волны $400 \mathrm{~nm}(3.1 \mathrm{eV})$.

Как можно увидеть из схемы возбуждения и регистрации люминесценции (рис. 1) и микрофотографии наностержней $\mathrm{ZnO}$ (рис. 2), при $\varphi=0$ абсолютное большинство наностержней направлены в сторону щели монохроматора и коллиматор собирает излучение, исходящее с торца наностержней. При этом необходимо также учесть возможный волноводный эффект в наностержнях. Из-за разности показателей преломления $\mathrm{ZnO}(2.2)$ и окружающего воздуха (1) возбужденная люминесценция канализируется в наностержне и на выходе собрана в определенном телесном угле. Как известно, экситонная люминесценция возбуждается во всем объеме, и большая ее часть канализируется в наностержне. Наличие направленности излучения выражается в уменьшении интенсивности экситонной люминесценции $(382 \mathrm{~nm})$ почти в три раза при изменении угла между нормалью к поверхности подложки с наностержнями и осью регистрации люминесценции от 0 до $63^{\circ}$. При этом появление и увеличение интенсивности фиолетовой ПЛ с ростом $\varphi$ указывает, что она не имеет выраженной направленности, т.е. слабо канализирована и исходит не из торца наностержня. С поворотом наностержней и их отклонением от оси регистрации на щель монохроматора попадает больше излучения, исходящего с боковых поверхностей наностержней. Это наблюдение позволяет предположить, что центры фиолетовой ПЛ преимущественно расположены на боковой поверхности наностержней. Это предположение хорошо согласуется с данными и выводами работы [18]. В этой работе на основе экспериментальных данных, полученных применением аннигиляции позитронов, было показано, что в 
пленках $\mathrm{ZnO}$ концентрация вакансий цинка уменьшается с увеличением толщины пленки. Этот результат является доказательством того, что центры вакансии цинка преимущественно расположены на поверхности или/и в приповерхностной области оксида цинка и больше подвержены эффектам, связанным с поверхностью. Конечно, с боковой поверхности наностержней излучается и экситонная люминесценция, но ее интенсивность по сравнению с таковой, излучаемой с торца, значительно меньше. Таким образом, различие в локализации источников экситонной и фиолетовой люминесценции в наностержня $\mathrm{ZnO}$ может являться причиной зависимости спектра от условий регистрации. Обнаруженное явление может найти применение в создании датчиков для определения пространственной ориентации объектов.

\section{Заключение}

С применением низкотемпературного гидротермального метода на стеклянных подложках, покрытых проводящей оксидной пленкой, синтезированы наностержни ZnO. В полученных наностержнях под воздействием УФ излучения возбуждается люминесценция при $382 \mathrm{~nm}$, когда наностержни ориентированы преимущественно параллельно оси регистрации. С изменением пространственной ориентации наностержней относительно системы регистрации излучения появляется фиолетовая ПЛ в районе $400 \mathrm{~nm}$. Увеличение угла между направлением роста наностержней и осью регистрации излучения приводит к росту интенсивности этой полосы и уменьшению интенсивности ПЛ при $382 \mathrm{~nm}$. Полоса люминесценции при $382 \mathrm{~nm}$ отнесена к краевой (экситонной) люминесценции $\mathrm{ZnO}$, а фиолетовая ПЛ к вакансиям цинка. Зависимость спектра люминесценции наностержней $\mathrm{ZnO}$ от их пространственной ориентации, возможно, связана с локализацией вакансий цинка в приповерхностных слоях наностержней, в то время как экситонная люминесценция возбуждается во всем объеме.

Работа выполнена при поддержке гранта № ОТ-Ф2-52 Программы фундаментальных исследований Республики Узбекистан.

\section{Список литературы}

[1] Özgür Ü., Alivov Ya.I., Liu C., Teke A., Reshchikov M.A., Doğan S., Avrutin V., Cho S.-J., Morkoç H. // J. Appl. Phys. 2005. V. 98. P. 041301.

[2] Yi G.C., Wang C., Park W.I. // Semicond. Sci. Technol. 2005. V. 25. P. 22.

[3] Huang M.H., Mao S., Feick H., Yan H.Q., Wu Y.Y., Kind H., Weber E., Russo R., Yang P.D. // Science. 2001. V. 292. P. $1897-1899$.

[4] Kurbanov S.S., Cho H.D., Kang T.W. // Opt. Commun. 2011. V. 284. P. $240-244$.

[5] Wu X.L., Siu G.G., Fu C.L., Ong H.C. // Appl. Phys. Lett. 2001. V. 78. P. 2285.
[6] Jeong S.H., Kim B.S., Lee B.S. // Appl. Phys. Lett. 2003. V. 82. P. 2625 .

[7] Hua G., Zhang Y., Ye Ch., Wang M., Zhang L. // Nanotechnol. 2007. V. 18. P. 145605.

[8] Kurbanov S.S., Panin G.N., Kim T.W., Kang T.W. // J. Luminesc. 2009. V. 129. P. 1099.

[9] Kumar B., Gonga B., Vicknesh S., Chua S.J., Tripathy S. // Appl. Phys. Lett. 2006. V. 89. P. 141901.

[10] Vanheusden K., Warren W.L., Seager C.H., Tallant D.R., Voigt J.A. // J. Appl. Phys. 1996. V. 79. P. 7983.

[11] Leiter F.H., Alves H.R., Hofstaetter A., Hofmann D.M., Meyer B.K. // Phys. St. Sol. (b). 2001. V. 226. P. R4.

[12] Heo Y.W., Norton D.P., Pearton S.J. // J. Appl. Phys. 2005. V. 98. P. 073502.

[13] Wu L., Wu Y., Pan X., Kong F. // Opt. Mater. 2006. V. 28. P. 418.

[14] Hsu J.W.P., Tallant D.R., Simpson R.L., Missert N.A., Copeland R.G. // Appl. Phys. Lett. 2006. V. 88. P. 252103.

[15] Djurišić A.B., Leung Y.H., Tam K.H., Ding L., Ge W.K., Chen H.Y., Gwo S. // Appl. Phys. Lett. 2006. V. 88. P. 103107.

[16] Kohan A.F., Ceder G., Morgan D., Van de Walle C.G. // Phys. Rev. B. 2000. V. 61. P. 15019.

[17] Erhart P., Albe K., Klein A. // Phys. Rev. B. 2006. V. 73. P. 205203.

[18] Zubiaga A., Tuomisto F., Plazaola F., Saarinen K., Garcia J.A., Rommeluere J.F., Zuñiga-Pérez J., MuñozSanjosé V. // Appl. Phys. Lett. 2005. V. 86. P. 042103. 